\title{
Erratum to: Shifts in Antarctic megabenthic structure after ice-shelf disintegration in the Larsen area east of the Antarctic Peninsula
}

\author{
Julian Gutt • Mattias Cape - Werner Dimmler • \\ Laura Fillinger $\cdot$ Enrique Isla $\cdot$ Verena Lieb \\ Tomas Lundälv $\cdot$ Christian Pulcher
}

Published online: 24 January 2014

(C) Springer-Verlag Berlin Heidelberg 2014

\section{Erratum to: Polar Biol (2013) 36:895-906}

\section{DOI 10.1007/s00300-013-1315-7}

In the original paper the labels of the abscissae of the plots shown in Fig. 6 (running years) were erroneously displaced. Here the corrected Fig. 6 is provided. The one-year shift in the year labels does not affect the general conclusions of the paper.

The online version of the original article can be found under doi:10.1007/s00300-013-1315-7.

J. Gutt $(\bowtie) \cdot$ L. Fillinger · V. Lieb · C. Pulcher

Alfred Wegener Institute Helmholtz Centre for Polar and Marine

Research, Columbusstr., 27568 Bremerhaven, Germany

e-mail: julian.gutt@awi.de

\section{Cape}

Scripps Institution of Oceanography, University of California, 8615 Discovery Way, La Jolla, San Diego, CA 92037, USA

\section{W. Dimmler}

Fielax Gesellschaft für wissenschaftliche Datenverarbeitung

mbH, Schleusenstr. 14, 27568 Bremerhaven, Germany

\section{E. Isla}

Institut de Ciències del Mar-CSIC, Passeig Marítim de la

Barceloneta, 37-49, 08003 Barcelona, Spain

V. Lieb

Christian-Albrechts-Universität Kiel, Christian-Albrechts-Platz 4,

24118 Kiel, Germany
T. Lundälv

Sven Lovén Centre for Marine Sciences, University

of Gothenburg, 45296 Strömstad, Sweden

C. Pulcher

Institut für Biologie und Umweltwissenschaften, Carl von

Ossietzky Universität Oldenburg, Carl-von-Ossietzky-Straße 9-11, 26129 Oldenburg, Germany 
Fig. 6 Mean sea-ice

concentration for a region of the Larsen A (a) and Larsen B

(b) embayments. Mean values appear as open circles, while the line represents a 7-day moving average. A threshold of $15 \%$ sea-ice concentration generally indicates open-water conditions. Areas of analysis are depicted in Fig. 1
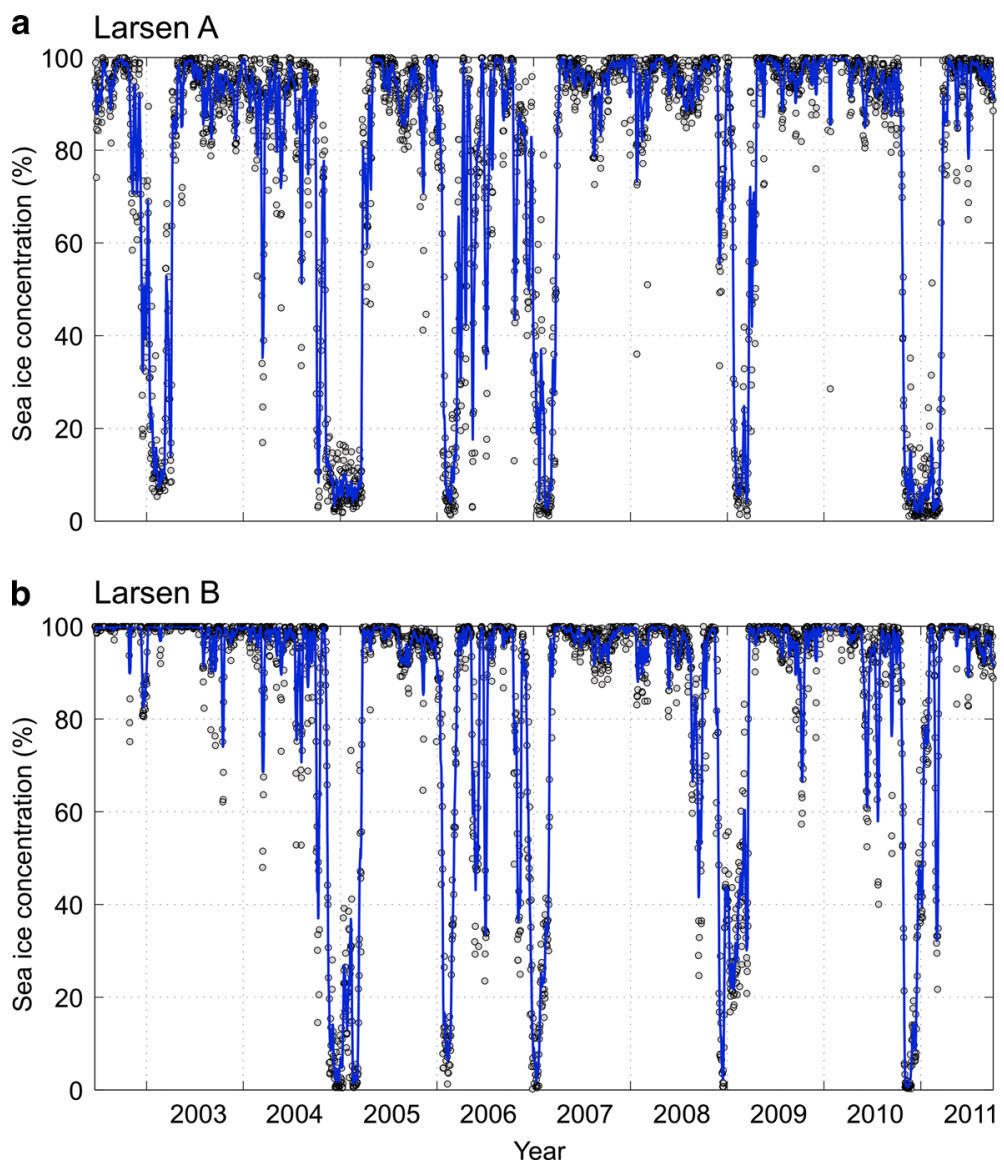